7. Reprod. Fert. (1970) 22, 21-25

\title{
ENZYMATIC MEASUREMENT OF PROSTATE GLAND FRUCTOSE
}

\author{
J. A. THOMAS, M. MAWHINNEY AND G. WENGER \\ Department of Pharmacology, \\ West Virginia University Medical Center, \\ Morgantown, West Virginia 26506
}

(Received 10th March 1969)

\begin{abstract}
Summary. Prostate gland fructose was measured enzymatically in normal and castrate mice. Regardless of protein precipitation procedure, castration resulted in a loss of prostatic fructose.

Prostate gland fructose levels were higher, using the resorcinol method, only when tricholoroacetic acid (TCA) was used to precipitate tissue proteins. Similar procedures employing supernatants obtained from barium hydroxide-zinc sulphate precipitated organs were comparable to enzymatically measured fructose.

The use of radio-active fructose and fructose-1,6-diphosphate established that heavy metal precipitation resulted in over $90 \%$ of the labelled fructose residing in the supernatant and a similar amount of phosphate ester found in the precipitate. The use of TCA to precipitate prostate gland proteins revealed that both fructose and fructose-1,6diphosphate were predominantly found in the supernatant (93 and $95 \%$ respectively). Very little radio-activity was found in the precipitate fraction, indicating that TCA was unable to separate free hexose adequately from phosphate esters.
\end{abstract}

\section{INTRODUCTION}

The inherent difficulties associated with various colorimetric methods for the determination of fructose have been the subject of numerous investigations (Dubois, Gilles, Hamilton, Rebers \& Smith, 1956; Yaphe \& Arsenault, 1965; Arsenault \& Yaphe, 1965; Davis \& Gander, 1967). Lindner \& Mann (1960) have reported that the use of heavy metals for protein precipitation provides the most satisfactory means for subsequent analyses of accessory sex gland fructose by colorimetric methods. These same investigators indicated that trichloroacetic acid (TCA) is unsuitable for the measurement of accessory sex gland fructose.

Previous studies from this laboratory have reported that TCA filtrates from mouse accessory sex organs yield higher colorimetrically determined fructose values than those tissues precipitated with barium hydroxide and zinc sulphate (Thomas, Mawhinney \& Mason, 1968). Recent studies using rat coagulating 
glands also showed that TGA filtrates contained more measureable fructose than filtrates obtained from heavy-metal-treated organs (Drori, Amir \& Folman, 1968). Thus, colorimetric methods, and particularly the resorcinol reaction, appear to be affected by types of tissue extraction or by the method of protein precipitation.

Because certain colorimetric procedures are generally considered to lack specificity, discrepancies arising from the use of TCA filtrates compared to those of heavy metals have been attributed to the presence of non-fructose resorcinol-reactive substances. Therefore, studies utilizing the enzymatic measurement of accessory sex gland fructose should exclude the possibility of interference from colour-reactive substances. The present investigations were undertaken to compare the levels of fructose found in mouse prostate glands as measured by the resorcinol method, or by an enzymatic procedure. Such a comparison was made in both normal, mature mice and at 3 days following castration. The effect of tissue extraction or protein precipitation (namely, organic acids versus heavy metals) on subsequent enzymatic analyses was also investigated. The separation of fructose from fructose phosphate(s) by either TCA or heavy metals was investigated further using tritiated fructose and ${ }^{14} \mathrm{C}$-labelled fructose-1,6-diphosphate as a carrier substance in the routine measurement procedures.

\section{METHODS}

Mature, male, albino mice were used throughout these investigations. Castrations, under ether anaesthesia, were performed by the abdominal route. Lobes of the anterior prostate gland (coagulating gland) were rapidly removed when the animal was killed and immediately placed between thin sections of dry ice. Weighed organs (pooled) were subsequently homogenized in cold $10 \%$ TCA, $6 \%$ perchloric acid or cold isotonic $\mathrm{KCl}$. Tissues homogenized in isotonic media were precipitated with $2 \%$ barium hydroxide and $1.8 \%$ zinc sulphate. Homogenates were centrifuged at $1000 \mathrm{~g}$ and the clear supernatants obtained from either the TCA-treated organs or the heavy-metal-treated tissues. Prostate gland fructose was measured by the resorcinol reaction (Roe, 1934) as modified by Lindner \& Mann (1960). The enzymatic measurement (Klotzsch \& Bergmeyer, 1963) of prostate gland fructose was carried out on supernatants obtained from either perchloric acid- or heavy-metal-treated tissues. The final $\mathrm{pH}$ of these supernatants was adjusted to 7.6. A $0 \cdot 2-\mathrm{ml}$ aliquot of this supernatant (equivalent to $8 \mathrm{mg} / \mathrm{ml}$ ) was employed in the final mixture. Hexokinase, glucose-6-phosphate dehydrogenase and phosphoglucose isomerase were obtained commercially (Sigma Chem. Co.). A Beckman DU spectrophotometer at a wavelength of $340 \mathrm{~m} \mu$ was used to measure the increase in optical density due to the formation of TPNH.

Labelled fructose $\left(2 \times 10^{-4} \mu \mathrm{c}\left[{ }^{3} \mathrm{H}\right]\right.$ fructose, New England Nuclear) was added directly to $4 \%$ homogenates (TGA or heavy metal), mixed and centrifuged. The supernatant and the pellet were counted for their radio-activity. Similarly, $\left[{ }^{14} \mathrm{C}\right]$ fructose-1,6-diphosphate $\left(2.4 \times 10^{-1} \mu \mathrm{c}\right)$ was added to prostate gland homogenates. Aliquots of supernatant were suspended in scintillation liquid and 
their radio-activity counted. The pellet was suspended in solubilizer (NGS solubilizer, Nuclear Chicago), digested, and scintillators added to the counting vial. Samples were corrected for quenching and background.

Endogenous fructose was expressed as $\mathrm{mg} / 100 \mathrm{mg}$ wet wt. Radio-active fructose values were calculated on the basis of the percentage of radio-activity found within either the supernatant or the pellet resulting from centrifuging at $1000 \mathrm{~g}$. A difference of means procedure was applied to compare the various experimental techniques (Snedecor, 1956).

\section{RESULTS}

The distribution of radio-active fructose and fructose-1,6-diphosphate added to homogenates of prostate gland that were subsequently precipitated with either

TABLE 1

DISTRIBUTION OF RADIO-ACTIVE FRUGTOSE ADDED TO HOMOGENATES OF MOUSE ANTERIOR PROSTATE GLANDS

\begin{tabular}{l|cc}
\hline \multicolumn{1}{c|}{ Radio-active sugar } & \multicolumn{2}{|c}{$\%$ of radio-activity } \\
& Supernatant $(1000 \mathrm{~g})$ & Precipitate \\
\hline $\begin{array}{l}\text { Trichloroacetic acid } \\
\text { extract } \\
\begin{array}{l}\left.{ }^{3} \mathrm{H}\right] \text { Fructose } \\
{\left[{ }^{14} \mathrm{C}\right] \text { Fructose-1,6-diPO }}\end{array}\end{array}$ & $93 *$ & \\
\hline $\begin{array}{l}\text { Barium hydroxide-zinc } \\
\text { sulphate extract } \\
{\left[{ }^{3} \mathrm{H}\right] \text { Fructose }}\end{array}$ & 95 & 5 \\
\hline$\left.{ }^{14} \mathrm{C}\right]$ Fructose-1,6-diPO & & \\
\hline
\end{tabular}

Labelled sugars were added to tissue homogenates $(4 \% \mathrm{w} / \mathrm{v}$ in cold isotonic KCL) in vitro. Mixtures of radio-active fructose and tissue homogenate were subsequently treated with either cold $10 \%$ TCA or heavy metals. See methods section for complete details.

* Average obtained for four experiments.

$10 \%$ TCA or barium hydroxide-zinc sulphate may be seen in Table 1 . It is evident that TCA will not separate fructose from its phosphate ester since both are found primarily in the supernatant fraction. The supernatant fraction from heavy metal protein precipitation contains predominantly fructose and not fructose-1,6-diphosphate. Therefore, the use of barium hydroxide and zinc sulphate will accomplish the separation of fructose from its phosphate ester(s). On the other hand, TCA is unable to separate the two forms of this ketohexose.

The results obtained from the use of radio-active sugars would indicate that adequate separation of fructose from fructose-1,6-diphosphate can be achieved with heavy metals. Assuming the use of an enzymatic technique for fructose measurement is specific, then the type of extraction procedure should not affect the resultant values obtained for this sugar. Such a relationship is revealed in Table 2. Regardless of protein precipitation procedures, there were no differences between the respective groups. Normal prostate glands precipitated with perchloric acid were similar to those treated with barium and 
zinc. Castration caused a typical reduction in the measureable amounts of fructose but again no differences between the methods of protein precipitation were observed.

Table 3 not only confirms the earlier reports pertaining to the higher levels of accessory sex gland fructose measured non-enzymatically on TCA-extracted organs (Drori et al., 1968; Thomas et al., 1968), but also reveals no differences in heavy-metal-treated organs regardless of the final method of measurement.

TABle 2

ENZYMATIC MEASUREMENT OF MOUSE PROSTATE GLAND FRUC-

TOSE USING TWO PROTEIN PRECIPITATION PROGEDURES

\begin{tabular}{l|lc}
\hline \multicolumn{1}{c|}{ Group } & \multicolumn{2}{c}{$\begin{array}{c}\text { Method of precipitation } \\
B a-Z n\end{array}$} \\
\hline Normals & Perchloric acid & $B .292 \pm 0.03$ \\
3-day castrates & $0.242 \pm 0.06$ & $0.292 \pm 0.02 * *$ \\
\hline
\end{tabular}

Mean values expressed as $\mathrm{mg} / 100 \mathrm{mg}$ wet $\mathrm{wt} \pm$ S.E. are based on eight or more animals

** Significantly lower than normals $(P \leqslant 5 \%)$.

TABLE 3

COMPARISON OF NORMAL PROSTATE GLAND FRUGTOSE LEVELS USING DIFFERENT METHODS OF TISSUE PRECIPITATION AND DIFFERENT METHODS OF MEASUREMENT

\begin{tabular}{|c|c|}
\hline $\begin{array}{r}\text { Enzymatically determined } \\
\text { Perchloric acid } \quad B a-Z_{n}\end{array}$ & $\begin{array}{c}\text { Non-enzymatically determined } \\
\text { TCA } \\
B a-Z n\end{array}$ \\
\hline $0 \cdot 242 \pm 0 \cdot 06$ & $0.547 \pm 0.01 * * \quad 0.271 \pm 0.01$ \\
\hline
\end{tabular}

Mean values expressed as $\mathrm{mg} / 100 \mathrm{mg}$ wet $\mathrm{wt} \pm \mathrm{S}$.E. are based on eight or more mice.

** Significantly higher than other procedures shown $(P \leqslant 5 \%)$.

It may readily be seen that enzymatically measured fructose (perchloric or heavy metal) was almost identical to resorcinol-determined fructose, when heavy metal protein precipitation procedures were employed.

\section{DISCUSSION}

These studies confirm the well-documented relationship between male sex hormone and accessory sex gland fructose. Whether prostate gland fructose is measured enzymatically or non-enzymatically, the amount of this hexose recedes quite rapidly following castration.

The use of enzymatic procedures to assess prostate gland fructose abolished differences in measureable levels of the sugar arising from different protein precipitation steps. Such differences continue to be present if fructose is subsequently measured by colorimetric techniques. TCA not only yields higher levels of accessory sex gland fructose, but filtrates of this organic acid also yield 
higher and somewhat unreliable results when used in the procedure for the colorimetric assessment of inulin (Highashi \& Peters, 1950; Fjeldbo \& Stamey, 1968).

Accessory sex organs contain not only fructose but fructose phosphate esters. These latter hexoses are involved in the phosphorylated pathway of fructose (Mann, 1963). There is little doubt that TCA is unable to separate free fructose from its phosphate esters. Colorimetric analyses of keto-hexoses in the supernatant of TCA-extracted tissues would give rise to additional chromogenic substances such as fructose-6-phosphate and fructose-1,6-diphosphate. These colour reacting substances can be eliminated by the use of heavy metals. The separation of fructose from its phosphate esters was readily demonstrated with the use of radio-active sugars. The specificity of the enzymatic procedures supports this latter finding.

\section{ACKNOWLEDGMENTS}

This work was supported in part by USPHS Grant 5 TO1 GM0007S.

\section{REFERENCES}

Arsenault, G. P. \& YAPhe, W. (1965) Effect of acetaldehyde, acetic acid and ethanol on the resorcinol test for fructose. Analyt. Biochem. 13, 1933.

Davis, J. S. \& Gander, J. E. (1967) A re-evaluation of the Roe procedure for the determination of fructose. Analyt. Biochem. 19, 72.

Drori, D., Amir, D. \& Folman, Y. (1968) Effect of mating and its frequency on the fructose content of the coagulating glands in rats. $\mathcal{F}$. Reprod. Fert. 16, 313.

Dubois, M., Gilles, K. A., Hamilton, J. K., Rebers, P. A. \& Smrth, F. (1956) Colorimetric method for determination of sugars and related substances. Analyt. Chem. 28, 350.

F Jeldbo, W. \& Stamey, T. A. (1968) Adapted method for determination of inulin in serum and urine with an autoanalyzer. F. Lab. clin. Med. 72, 353.

Highashi, A. \& Peters, L. (1950) A rapid colorimetric method for the determination of inulin in plasma and urine. F. Lab. clin. Med. 35, 475.

Klotzsch, H. \& Bergmeyer, H. (1963) Methods in enzymatic analysis, p. 156. Academic Press, New York.

Lindner, H. R. \& MANN, T. (1960) Relationship between content of androgenic steroids in the testes and the secretory activity of the seminal vesicles in the bull. 7. Endocr. 21, 341 .

ManN, T. (1963) Biochemistry of the semen and of the male reproductive tract, p. 237. Wiley, New York.

ROE, J. H. (1934) A colorimetric method for the determination of fructose in blood and urine. F. biol. Chem. 106, 15.

SNedecor, G. W. (1956) Statistical methods, p. 90. Iowa State College Press, Ames, Iowa.

Thomas, J. A., Mawhinney, M. \& Mason, W. (1968) Sex accessory fructose: an evaluation of biochemical techniques. Proc. Soc. exp. Biol. Med. 127, 930.

YAPHE, W. \& ARSENAUlt, G. P. (1965) Improved resorcinol reagent for the determination of fructose and of 3,6-anhydrogalactose in polysaccharides. Analyt. Biochem. 12, 143. 